\section{Significados atribuídos à vivência materna como acompanhante do recém-nascido pré- termo e de baixo peso}

\section{Meaning attributed to the experience of mothers accompanying hospitalized premature and low birthweight newborns}

Maria Gorete Lucena de Vasconcelos 1

Adriana Moraes Leite 2

Carmen Gracinda Silvan Scochi 3
1 Departamento de Enfermagem. Universidade Federal de Pernambuco. Rua Prof. Moraes Rego, s. n. Cidade Universitária. Recife, PE, Brasil. CEP: 50.670-901.

E-mail: mariagorete47@hotmail.com

2,3 Departamento de Enfermagem Materno-Infantil e Saúde Pública. Escola de Enfermagem de Ribeirão Preto. Universidade de São Paulo. Ribeirão Preto, SP, Brasil.

\begin{abstract}
Objectives: to identify the meaning of being an accompanying mother to a hospitalized premature and low birthweight newborn and participant of a multidisciplinary support group.

Methods: qualitative research performed through a descriptive exploratory study at the Hospital das Clínicas da Universidade Federal de Pernambuco with data collected through observation and taped interviews with 16 accompanying mothers of hospitalized infants in the period of March to December, 2003. According to inclusion criteria to theoretical saturation in response to two guiding questions, content analysis through cross sectional thematic analysis was made.

Results: age of women varied between 15 and 28 years old and eleven of them already had children. Based on maternal perception of the experience, four core themes were identified: suffering caused by family separation and support deprivation; maternal facilities viewed as a prison not permitting discharge without the child and as a place for new friendships, advice and conflicts.

Conclusions: the study suggests a humane need to caring. A collectively and positively learning within a formal context might serve as an input for different realities.
\end{abstract}

Key words Prematurity, Infant, low birth weight, Mother with child in hospital, Self-help groups

\section{Resumo}

Objetivos: identificar o significado de ser mãe acompanhante do recém-nascido pré-termo e de baixo peso, em participantes de um grupo de apoio multidisciplinar.

Métodos: pesquisa qualitativa, realizada por meio de estudo descritivo e exploratório. O contexto da investigação foi o Hospital das Clínicas da Universidade Federal de Pernambuco, sendo os dados coletados por meio da observação e entrevista gravada com 16 mães acompanhantes, no período de março a dezembro de 2003, seguindo critérios de inclusão até a saturação teórica, em resposta a duas questões norteadoras. Utilizou-se a análise de conteúdo, na modalidade análise temática transversal.

Resultados: a idade das mães variou entre 15 e 28 anos e 11 delas já tinham um filho. A partir da percepção materna acerca da experiência vivida, foram identificados quatro temas: o sofrimento pela separação da família e o apoio recebido; o alojamento materno como prisão; a não admissão da possibilidade de alta sem o filho e o alojamento materno enquanto espaço de novas amizades, aconselhamento e conflitos.

Conclusões: o estudo aponta para a necessidade da ação humana de cuidar. O aprendizado coletivo se dá de forma concreta e positiva num contexto formal, podendo servir como subsídio para outras realidades.

Palavras-chave Prematuridade, Recém-nascido de baixo peso ao nascer, Mãe acompanhando filho no hospital, Grupos de auto-ajuda 


\section{Introdução}

A análise da situação da morbimortalidade infantil permite compreender graves problemas que persistem no Brasil, desafiando os serviços de saúde e a sociedade. Apesar de a mortalidade infantil haver decrescido significativamente com a implantação dos programas de promoção à saúde na década de 90, a redução mostrou-se mais expressiva no período pós-neonatal, com predomínio da mortalidade neonatal. As afecções perinatais representam $72 \%$ da mortalidade neonatal e entre elas destacam-se a prematuridade e o baixo peso ao nascer (BPN). ${ }^{1}$

As internações dos recém-nascidos pré-termos (RNPT) representam um número expressivo nas unidades neonatais, devido ao risco de adaptação dessas crianças à vida extra-uterina, decorrentes da imaturidade anátomo-fisiológica e do próprio processo de diagnóstico e da terapêutica. O RNPT pode apresentar uma série de complicações, após o nascimento, e, muitas vezes associado à prematuridade encontra-se o BPN, acentuando ainda mais os riscos de morbimortalidade infantil.2-4

As modernas unidades de terapia intensiva neonatal, equipadas com tecnologia de ponta, são um marco na assistência ao recém-nascido de risco, contribuindo para a sua sobrevida e tendo como foco da assistência os aspectos biológicos, primordialmente. Nos dias atuais, esse tema vem sendo discutido com frequiência entre os profissionais e as instituições de saúde, com a finalidade de transformar tal realidade, ampliando e focalizando a assistência à tríade mãe/filho/família. Scochi 5 informa que entre os fatores de risco fisiológicos relacionados à prematuridade, acham-se envolvidas também dimensões sociais, políticas e institucionais. E que a noção de risco individual passa por uma nova compreensão, a de vulnerabilidade social.

No ciclo familiar não existe estágio algum que provoque mudança mais profunda, ou que tenha um desafio maior para as famílias do que a chegada de uma criança. No caso do nascimento de um recémnascido de risco, seja prematuro ou doente, a família se vê frente a uma experiência desgastante e desafiadora, o que ocasiona profundas alterações na dinâmica familiar, e se prolonga com a internação do filho.6,7 $\mathrm{O}$ tempo de internação do RNPT/BPN na unidade neonatal se estende por vários meses, e, no cenário dessa hospitalização prolongada, ocorre uma mudança súbita na vida da família, especialmente da mãe, que num curtíssimo espaço de tempo torna-se acompanhante do filho, sem que esteja preparada para essa mudança, quase sempre permeada por muito sofrimento. Na busca de uma assistência voltada para a humanização nas unidades neonatais, Lamy et al., 8 mencionam como os pais percebem a internação dos filhos, recomendando que esses devem ter um espaço para perguntar, ouvir e relatar suas necessidades individuais.

A ausência de intervenções direcionadas à mãe acompanhante, para ouvi-la e apoiá-la nesse difícil processo de ter um filho prematuro internado em uma unidade de alta complexidade assistencial, não atende suas necessidades de mulher inserida numa família concreta, vivenciando momentos difíceis no processo do nascimento de modo súbito. O enfoque da assistência nos serviços materno-infantis está centrado nos aspectos biológicos do ato de amamentar, priorizando como função única da mulher a de produzir leite para nutrir o filho, e necessita ser revisto para que se amplie o objeto de ação para além do corpo anátomo-fisiológico, a fim de que a mulher não seja vista como um ser isolado do seu contexto social. ${ }^{9}$ A comunicação, nesta perspectiva, é um recurso terapêutico que dá acesso à autonomia, à confiança mútua e à segurança, permitindo estabelecer interações entre a equipe de saúde e a tríade familiar. E, como um desafio na busca da qualidade da assistência, essa ferramenta orienta as intervenções e consolida uma concepção do fazer saúde no contexto hospitalar. 10

$\mathrm{O}$ estudo que ora se apresenta faz parte de um trabalho mais amplo, 11 que tem como objetivo identificar o significado de ser mãe acompanhante do RNPT/BPN no cotidiano vivido. A relevância consiste em elucidar as falas na busca da reconstrução de uma prática integral e humanizada, procurando minimizar os efeitos da permanência materna prolongada no Hospital das Clínicas da Universidade Federal de Pernambuco.

\section{Métodos}

Trata-se de um estudo descritivo e exploratório, realizado através de uma pesquisa qualitativa que tentou identificar significados atribuídos no processo de ser mãe acompanhante de bebês prematuros, tentando incorporá-los de modo intencional na dinâmica das relações sociais no ambiente hospitalar. Ao se trabalhar com o conhecimento da experiência e da vivência, acredita-se fornecer subsídios para intervir na realidade buscando avançar qualitativamente, mudando condições percebidas como transformáveis.12-14 A motivação adquirida pelo conhecimento teórico-conceitual construído na perspectiva do cuidado integral e humanizado foi o ponto de partida para enfrentar esse desafio acadêmico. 
O contexto da investigação foi o Hospital das Clínicas da Universidade Federal de Pernambuco (HC/UFPE), em Recife, titulado como "Amigo da Criança". Esse hospital dispõe de seis leitos para mães acompanhantes do recém-nascido de risco, localizado próximo à Unidade de Internação Neonatal (UIN), cumprindo o que determina o Estatuto da Criança e do Adolescente. 15 Esses leitos constituem um alojamento específico e oferecem às mães condições para que após a alta da maternidade permaneçam no hospital em tempo integral durante a internação prolongada do filho na unidade neonatal. A alta hospitalar do RNPT/BPN está na dependência da estabilidade clínica, do ganho de peso e do estabelecimento e manutenção do aleitamento materno exclusivo.

Para coleta de dados utilizou-se a observação e a entrevista, recursos escolhidos pela natureza do problema estudado, compreendendo os meses de março a dezembro de 2003. No sentido de apreender os significados emergidos das falas foi realizada uma entrevista aberta não-estruturada que permitiu à mãe narrar os fatos e as particularidades relativas à experiência de modo natural,16 guiada pela seguinte questão norteadora: "Como você se sente sendo mãe acompanhante do seu filho logo após o parto?"

Os dados da observação foram registrados em um diário de campo, sendo a entrevista gravada com a autorização das mães e realizada em local privativo, uma sala de reunião do hospital, localizada no mesmo andar da UIN, com duração média de 35 minutos. Após a gravação as falas foram transcritas na íntegra, sem as convenções da língua padrão culta, identificando os sujeitos por um codinome em ordem alfabética seqüencial para preservar o anonimato, porém, com registro de alguns dados necessários à caracterização da amostra: idade, número de filhos, escolaridade, ocupação e situação marital, e gênero, Apgar do $1^{\circ}$ e $5^{\circ}$ minutos, peso ao nascer e idade gestacional do filho.

Com base no processo de amostragem qualitativa, 16 foi selecionada intencionalmente a amostra entre as participantes do Grupo de Apoio às Mães Acompanhantes (GAMA) da UIN/HC/UFPE e estabelecidos os seguintes critérios de inclusão para a mãe: aceitar voluntariamente participar da pesquisa; ter o filho prematuro e de baixo peso assistido na unidade de internação neonatal por período igual ou superior a sete dias; estar de alta hospitalar permanecendo no alojamento materno, acompanhando o filho, e ter participado no mínimo de cinco reuniões do grupo citado acima. As inclusões foram dadas até a saturação teórica 12 tendo atingido esse ponto com a entrevista de 16 mães participantes do grupo.
Não houve recusa na participação da entrevista, frente à relação construída ao longo do desenvolvimento das reuniões do GAMA, quando foram eliminadas as barreiras de comunicação 16 com as participantes.

Um fator facilitador foi o curso de Capacitação para Coordenadores de grupos operativos, ministrado no hospital que forneceu subsídios para condução do trabalho de coordenação no grupo de apoio. Outro fator facilitador decorreu da percepção frente à necessidade da mãe ser ouvida pela equipe de saúde, sobre a dupla experiência vivida no pósparto: o nascimento do filho prematuro e a condição de ter que permanecer acompanhando o filho durante a sua hospitalização, até a alta. A atuação nas reuniões do grupo se constituiu em um ensaio preliminar para aperfeiçoar a qualidade na coleta dos dados, sendo considerado o estudo piloto.

A limitação do estudo se deu pelo fato da entrevista ser realizada com as mães ainda no contexto hospitalar antes da alta do recém-nascido, o que pode ter potencializado bias de informação, durante a realização da mesma. Isso não invalidou o procedimento de coleta e análise, mas sinalizou para uma adequação em estudos futuros.

No tratamento dos dados foi utilizada a análise de conteúdo, modalidade de análise temática transversal que recorta as falas, levando em conta a frequiência dos temas extraídos dos discursos, descobrindo núcleos de sentido que compõem a comunicação e cuja presença dá significado ao objetivo da análise, elegendo a seguir as categorias ou temas. 17

Cada entrevista foi operacionalizada separadamente, e durante a transcrição optou-se pela seguinte padronização ou legenda para situar as falas: [_] pausa durante a fala, $[\ldots]$ recortes de outras falas, ... recorte na mesma fala, ( ) observações complementares de conteúdos e comportamentos nãoverbais, segundo Bardin. 17

Atendendo à Resolução no 196 do Conselho Nacional de Ética em Pesquisas (CONEP) com seres humanos, realizou-se o estudo após o recebimento do parecer favorável do comitê de ética do Centro de Ciências da Saúde ocorrido em 6 de novembro de 2002. Foi solicitada previamente às mães a autorização para coleta de dados, através da assinatura do Termo de Consentimento Livre e Esclarecido e para as mães adolescentes foi feita a mesma solicitação a ela e ao seu responsável. 


\section{Resultados}

A idade das 16 mães acompanhantes que fizeram parte do estudo variou de 15 a 28 anos e a escolaridade da primeira série do ensino fundamental até a $11^{\text {a }}$ série ou segundo grau completo; onze das entrevistadas tinham um filho, incluindo o atual, e com relação à ocupação nove exerciam suas atividades no lar; duas eram estudantes e cinco trabalhavam fora do domicílio, sendo duas domésticas, uma manicure, uma garçonete e uma secretária. Destas, apenas duas tinham carteira assinada. Quanto à situação marital, oito mães viviam em união consensual, cinco eram casadas e três solteiras. Apesar de não ter sido investigada a renda familiar, a maioria das mães informava ter baixo poder aquisitivo, característica compatível com o perfil da clientela do hospital estudado.

Entre os recém-nascidos, quatro eram gemelares (RNs de Ana e Elaine), nove eram do sexo masculino e nove do sexo feminino. O Apgar no primeiro minuto variou de três a nove e no quinto minuto de seis a dez, enquanto o peso ao nascer ficou compreendido entre 810 e 1945 gramas, estando à idade gestacional entre 31 a 36 semanas. Um dos $\mathrm{RN}$ foi a óbito.

Os resultados apontaram inicialmente que o significado de ser mãe acompanhante do RNPT/BPN se consistiu numa experiência difícil, ruim, dolorosa; sendo permeada por sentimentos de tristeza, medo e insegurança; sentimentos comuns não apenas entre as primíparas, como também entre as que já possuíam outros filhos, como Dália e Leila. Por sua vez, a hospitalização do recém-nascido ocasionava desgaste físico e mental, especialmente associado ao desejo que elas manifestavam de retornar ao lar. Os depoimentos abaixo revelaram a situação:

"Primeiro lugar, foi muito difícil. Era

péssimo, eu só ficava chorando." (Dália)

"... medo, o que ficou comigo do

começo até o fim, foi medo. Eu ficava muito insegura." (Flávia)

"... Tristeza, queria ir para casa... foi ruim pra mim." (Hortênsia)

"... Difícil demais ... dá vontade de descer e ir embora, deixar tudo aí \{...\} não é fácil ficar, ser mãe acompanhante." (Leila)

"... Tenho medo ... e hospital não é bom. É difícil, não é bom, a gente fica doida pra ir pra casa. É uma experiência dolorosa, nunca mais vou esquecer!" (Quitéria)

A partir dessa percepção inicial da mãe acerca da experiência vivida, foram identificados quatro núcleos temáticos: a) o sofrimento pela separação da família e o apoio recebido; b) O alojamento materno como prisão; c) não admissão da a possibilidade de alta sem o filho, e d) o alojamento materno enquanto espaço de novas amizades, aconselhamento e conflitos.

\section{O sofrimento pela separação da família e o apoio recebido}

Com a permanência prolongada a saudade da família foi um sentimento marcante entre as mães, principalmente com relação aos familiares mais próximos, pois a hospitalização do filho na unidade neonatal estabeleceu uma condição imediata ao receber alta da maternidade, a de ter que acompanhar o filho. Isso se deu em um curto espaço de tempo, sem que elas fossem orientadas adequadamente sobre o que aconteceria a partir dessa condição. Entre as entrevistadas, a permanência na instituição variou de 26 a 83 dias. Essa permanência aumentava a distância, o contato com os familiares e a separação estava ocorrendo para algumas pela primeira vez. Pois, sendo o hospital referência para o atendimento da gestação de risco, recebe pacientes do interior do estado e de outros estados vizinhos. Como o poder aquisitivo era baixo, isso ocasionava um alto custo para o deslocamento dos familiares até o hospital, intensificando o sofrimento dessas mães, pela dificuldade em receber visitas diárias. Como para Beatriz, que nunca havia se separado da família e residia no interior, sofrendo com muita saudade dos seus entes queridos.

"Eu acho que vou endoidecer se ficar aqui (refere-se ao hospital chorando) ... Esse tempo todinho aqui, ficando direto. I...। Saudade do povo de casa, do meu marido, dos meus irmãos, da minha mãe. Eles num pode vim todo dia, porque a passagem é cara." (Beatriz)

Por sua vez, Quitéria, que também residia numa cidade do interior mais próxima do centro, recebendo visitas mais frequientes do marido, relatou sua experiência, chorando.

"I...। Fico pensando: tá sózinha (chora), sem ninguém perto de mim, sem família, longe. Sou muito apegada, que eu vivia antes ia pra casa da minha mãe todo dia, e a noite ia esperar $G$ (marido) chegar. Quando me lembro dessas coisas dá vontade de chorar." (Quitéria)

Apesar de algumas das mães residirem na região metropolitana do Recife, a separação da família também demonstrava ser sofrida, pela vastidão de eventos. 
"... junta o nenê que tá doente, você que tá só, a família que tá em casa, a saudade, né? E o dia a dia longe (balança a cabeça, negativamente)." (Gerusa)

"... eu nunca convivi longe da minha mãe, do meu pai, dos meus irmãos ... do meu marido também." (Maria)

"Porque eu tô longe da família, né? Porque tem que ficar aqui (hospital). Tô longe da minha família, longe dos meus filhos, né?" (Paula)

Sentindo-se impossibilitadas de exercerem as atividades rotineiras junto à família, especialmente de cuidar dos familiares e da casa, elas verbalizaram nas falas suas preocupações e necessidades. A possibilidade dessas mulheres serem ouvidas foi a estratégia adotada que se contrapôs ao modelo biologicista, uma vez que essas mães são sujeitos sociais, inseridas em famílias concretas. Nesse sentido, os conflitos advindos dos diferentes papéis exercidos pelas mulheres na sociedade como mãe, esposa, dona-de-casa, profissional, influenciavam e exacerbavam o desgaste emocional. Elas se descobriram tendo que deixar a vida lá fora e querendo cumprir seus deveres.

"A gente abre mão de muita coisa pra ficar aqui! (referindo-se ao hospital)! De ficar em casa cuidando do outro filho da gente que ficou em casa, do marido, da família." (Ana)

"Porque a gente deixa as coisas em casa pra ficar aqui (hospital)! com eles (filhos gêmeos). Deixa marido, filho, casa pra arrumar ... Porque minha menina em casa, também precisa de mim e meu marido." (Elaine)

" I... porque eu tive que deixar tudo, pra ficar com ela (filha), minha casa, minha vida. Não imaginei que iria passar por isso!" (Nilce)

Carolina que tinha 15 anos, era solteira e estudava, manifestou-se de modo inusitado diante da nova situação como mãe e acompanhante do seu primeiro filho:

"I... I sinto falta da minha vida lá fora, sinto falta da minha família, dos meus amigos, tudinho. Sinto falta até do colégio!" (Carolina)

Assim, no contexto do alojamento materno, elas discutiam entre si sobre a situação imposta, chegando a perceber que as maiores dificuldades eram enfrentadas por aquelas que tinham outros filhos ou trabalhavam fora. Leila, mãe pela terceira vez de prematuros, que trabalhava como manicure para sustentar os filhos, sem o apoio legal trabalhista, sentia agravada a situação em que se encontrava.

"I... I Era muita mãe reclamando dentro do quarto, muita mãe chorando, porque passava muito tempo aqui dentro (alojamento materno) e quem tem filho fora? Quando é o primeiro, tudo bem, tudo é ótimo ... E quem tem dois, já? E, quem trabalha, também. Sem poder ir embora!" (Leila)

$\mathrm{O}$ apoio da família foi um recurso fundamental e o primeiro a ser acessado pelas mães no sentido de verem atendidas algumas das suas necessidades mais simples. Logo, Gerusa, que trabalhava como garçonete e se mostrava muito dinâmica, sendo inclusive, convidada pelo grupo de apoio a ensinar ponto de cruz às companheiras de alojamento, atividade muito bem aceita pela mesma, percebendo a possibilidade da internação do seu filho se prolongar, recorreu, rapidamente, ao apoio da sua mãe.

"Então, eu fiz uma coisa, liguei pra casa: - mainha traz logo alguma coisa, caneta, papel, lápis de cor, livros, gibi, revista de ponto de cruz, um radinho, qualquer coisa, mãe. Traga, porque, se não eu não vou agüentar ficar." (Gerusa)

Para Isabel, o apoio dos seus familiares auxiliou no processo de permanência junto ao filho hospitalizado. A mesma residindo no interior do estado, relativamente distante da capital e cuja família dispunha de uma condição socioeconômica diferenciada em relação à maioria, era visitada com maior frequiência pelos entes queridos, fazendo questão de frisar o apoio recebido deles, embora, continuasse admitindo ser a experiência difícil.

"I... I com a ajuda da minha família, que aqui (hospital) ela tá me ajudando, tá me dando apoio, mais tô distante dela e foi muito difícil." (Isabel)

O que acontece no contexto estudado deve-se à ausência de estratégias sistematizadas de apoio formal à mãe acompanhante do RNPT/BPN e sua família. Essas mães, ao saírem de alta hospitalar são alojadas, não recebendo nenhum suporte do serviço, inclusive visitas da equipe de saúde. Na maioria das vezes, as iniciativas de apoio são pontuais, partindo de alguns profissionais sensíveis à questão.

\section{O alojamento materno como prisão}

A sensação de viver isolada numa prisão, com limitação de espaço e relações, sem ter com quem conversar, foi manifestada principalmente por Ana, 
que permaneceu 83 dias no alojamento materno. Ela deu a luz a dois meninos gêmeos, e tinha uma filha de seis anos que estava sob os cuidados da sua mãe no domicílio. Seus filhos prematuros pesaram ao nascer 810 e 990 gramas, permanecendo um maior tempo para iniciarem o aleitamento e adquirir o peso adequado para alta.

"A gente fica aqui presa, não sai pra canto nenhum ... fica presa, fica isolada do mundo lá fora ... numa prisão! Eu mesma me sinto presa, como se eu tivesse feito alguma coisa e estivesse presa. Porque a gente só fica assim do quarto pro berçário, do berçário pro quarto." (Ana)

Outras mães que não foram entrevistadas também reforçaram esse desabafo, com as colegas de quarto, como podemos perceber na fala de Gerusa, descrevendo o desabafo de uma delas, que potencializou sua percepção de ser o alojamento materno semelhante a uma prisão.

"... hoje tinha uma colega nossa de quarto, que ela disse assim: É, meu Deus, a gente deu a vida a uma pessoa e está presa, a gente não matou (sorri com euforia). /.../ Porque isso é uma prisão, tem hora que eu sinto uma prisão, a gente deu vida a alguém, não matou alguém. Então, a gente não merece tá presa aqui! ... ela dizia isto e a gente achava engraçado. Porque, realmente era como a gente se sentia, presa. /.../ (fala com firmeza). G. dizia, né: a gente deu vida a alguém, não matou alguém (demonstra tristeza), a gente fica presa, por quê?" (Gerusa)

Para Joana, que era casada e trabalhava como secretária no mesmo local de trabalho do esposo, a experiência de ter que viver no alojamento materno, retratou sentimentos de angústia e medo na fala a seguir:

"A pessoa num local como esse aqui se abate, e a experiência não é boa não. $\mathrm{Na}$ realidade não é boa ... A gente se angustia

... muita angústia, e medo." (Joana)

$\mathrm{O}$ alojamento materno localiza-se no quarto andar do setor da maternidade, possuindo dois quartos, cada um com três leitos. A vista das janelas fica obstruída pelo telhado de um bloco do hospital, impossibilitando ou dificultando a visão da área externa por onde circulam as pessoas. Esse fato não passou despercebido entre elas:

"No quarto que eu tô, você não vê nem a rua, né, só vê carro, porque dá pra vê o estacionamento, se não nem via isso ..." (Gerusa)

Nesse isolamento, as mães passavam a contar com minúcia os dias que permaneciam acompanhando o filho, dando relevo à fala, ou contando nos dedos o tempo de permanência no ambiente hospitalar, demonstrando que cada dia, cada semana, cada mês do período transcorrido era enfaticamente valorizado.

"Tô há um mês e uma semana (aumenta a entonação da voz), eu pensava que ia ficar mais pouco." (Beatriz)

"Aí, foi uma surpresa, eu tava pensando: Ah! Eu vou ter meu filho e vou embora para casa (sorri). Mas não, tive que ficar um período (a voz soa forte) até agora, 28 dias." (Dália)

"... eu nem sabia que ia ser mãe acompanhante, nem jurava que eu ia ficar tanto tempo, um mês aqui dentro (fala com firmeza). Pra mim, foi péssimo!" (Leila)

"I ...। 25 dias hoje (conta nos dedos)." (Maria)

"E, já faz um bom tempo que eu tô aqui, um mês e nove dias (voz firme)." (Nilce)

Por outro lado, a sensação de estar presa e a contagem dos dias de permanência no alojamento materno longe do filho, era minimizada quando ambos podiam ficar juntos na ocasião em que mãe e filho eram transferidos para o alojamento conjunto, mesmo que essa permanência pudesse se estender por mais algum tempo.

"De repente trouxeram ela (filha). Eu

digo: agora sim, tô satisfeita, eu passo até dois meses aqui (sorri), porque ela está aqui ao meu lado." (Joana)

"Hoje eu tô aqui com meu filho (sorri) ... e espero sair em breve daqui." (Maria)

Mesmo detendo o título de "Hospital Amigo da Criança" a organização do serviço deixa de atender algumas necessidades dos prematuros e da família, pela não existência do método "Mãe-Canguru", que se constitui numa estratégia essencial para mudança institucional na perspectiva da humanização da assistência, promoção do aleitamento materno exclusivo e fornecimento de direitos de cidadania à criança e sua família.

\section{Não admissão da possibilidade de alta sem o filho}

Apesar de sentirem o hospital como uma prisão e de sofrerem com a separação da família, algumas mães não admitiam a possibilidade de alta sem o filho, por não terem coragem de deixá-lo.

Olga, 20 anos, mãe pela primeira vez, clarifica 
bem esse núcleo temático:

"... com certeza ao lado da minha filha.

Jamais eu iria para casa e deixar ela aqui."

(Olga)

O medo de sentir-se culpada pela ocorrência de um evento fatal no período de ausência do hospital, contribuiu para que Carolina não retornasse às suas atividades escolares enquanto o filho permanecia internado em estado grave. Somente após o filho ter ido a óbito, ela deixou o hospital, tendo que encarar a nova realidade.

"I...I mas eu prefiro ficar aqui com ele (filho) do que ir embora e acontecer alguma coisa com ele que eu vou me sentir culpada, se isso acontecer." (Carolina)

Havia demonstração de luta persistente travada entre as mães dos recém-nascidos mais graves, mesmo entre aquelas que tinham outros filhos, sendo prioridade o filho internado, como se expressam Leila e Paula. Elas percebem que podem oferecer às filhas um cuidado exclusivo, o carinho.

"I...। Se vai passar três meses ... eu só saio daqui de dentro (hospital) com minha filha, ou boa, ou se vai se fechar os olhos também, tudo bem, ou se com a saúde dela. Daqui eu não saio nem por dinheiro nenhum, só saio com ela nos braços, agora eu fico aqui, não tão passando sem eu, ficam sem passar até eu chegar em casa (referindo-se aos filhos que estão em casa)." (Leila)

"Em casa tem quem cuida dos outros (filhos), né? E, aqui só quem tá podendo cuidar dela sou eu. Dar o carinho, só eu." (Paula)

Por outro lado, quando a possibilidade de alta do filho poderia depender do estabelecimento e manutenção do aleitamento materno exclusivo e da habilidade para cuidar do bebê, havia mães que demonstravam ansiedade, porque entendiam que o período de permanência poderia se prolongar. Uma delas, Beatriz, chegou a comparar sua produção láctea a de outras mães, mesmo tendo recebido o mesmo treinamento pela equipe do banco de leite, como descrito:

"Se ela (neonatologista) dizer, assim, que vai sair só quando eu tiver leite, eu não vou sair nunca daqui (hospital). Porque, eu não vou ter, eu acho ... Eu não tenho (leite) de jeito nenhum. \{ \} Num tem aqueles copinho de plástico? Eu não tiro um daquele cheio durante o dia, eu tenho? Mais tem mulê, que tem. C. (mãe acompanhante) mesmo, tem que só! Aquela outra menina (mãe acompanhante), que tá no quarto da gente, também tem um pouco ... O menino dela nunca tomou leite, só o dela mesmo ... do jeito, que ela (C.) fazia, eu fazia também. Que a mulê do banco de leite me ensinou, assim, tirar de três em três horas (demonstra tristeza) ... Sei não, eu fico só pensando em ir embora, eu não vou me acostumar."

(Beatriz)

A ansiedade gerada muitas vezes dificultava a adoção de uma prática que beneficia a mãe e o filho, com o estabelecimento e a manutenção do aleitamento exclusivo. Mas acredita-se que a prática impositiva no ambiente hospitalar não garante sua manutenção no domicílio.

\section{O alojamento materno enquanto espaço de novas amizades, aconselhamento e conflitos}

Ao receberem suporte através do grupo de apoio no ambiente hospitalar, durante os longos períodos de permanência, houve o favorecimento de ações que possibilitaram estabelecer novas amizades, trocarem experiências, apoiarem-se e acolherem-se mutuamente, diante das necessidades presentes.

"... eu tenho aquela necessidade que

alguém de fora me ouvisse, né. Entendesse,

pelo menos, ou me explicasse o porquê. /_

Foi à primeira vez que alguém parou pra ouvir o que eu tinha passado mesmo."

(Gerusa)

O processo contribuiu para uma melhor adaptação ao ambiente aparentemente tão hostil, como também aliviou as tensões, permitindo transformar a realidade vivida.

"Bom, no começo eu fiquei um pouquinho calada, mas eu acho que depois eu até ajudei alguém, como também me ajudaram, né? A gente conversava. \{ \} No início era aquela tensão, mas depois quando a gente ia trocando os problemas, ia conversando. E, como também dividir, compartilhar, eu acho que melhora, fica mais leve. ( ) Quando a gente fez logo o ciclo de amizade, passou a conhecer mais uma a outra, era divertido. Era bom ter a companhia uma da outra, conversar, desparecer [espairecer] um pouquinho." (Flávia)

A troca de experiência se deu independentemente da idade das mães, ou da experiência vivida. Não importava se o apoio vinha de uma mãe de primeiro filho para uma mãe que já havia tido outros filhos ou tivesse mais idade. $\mathrm{O}$ que marcou foi a 
busca para minimizar o sofrimento da companheira. O estímulo do grupo para se apoiarem mutuamente fez diferença.

"I...I você faz amizade, você conhece outras pessoas, sabe da vida das meninas (mães acompanhantes) ... contavam tudo pra mim ... Ficavam tudo conversando, contavam briga dos maridos, como que foi a gravidez, tudo. A gente botava as mágoas em dia, conversava tudo sobre os bebês ... Uma das mães me deu muitos conselhos (cita Isabel). Porque a filha dela passou pelo mesmo processo da minha. Ela (Isabel) disse: -' não desespere porque eu passei por tudo isso, eu chorava muito, mas eu passei por tudo isso ... tive um apoio (fazendo referência ao grupo de apoio) e foi ótimo pra mim' (conclui a fala da colega) / / Eu acho que respirei melhor e fiquei sentindo melhor a convivência." (Leila)

$\mathrm{O}$ apoio às mães acompanhantes se deu de modo formal e informal, durante a permanência no hospital, uma vez que se sentiram apoiadas pelos profissionais e pelas novas amizades construídas.

"E, graças a Deus, eu fiz muita amizade (refere-se às companheiras do alojamento). I...I (referindo-se a equipe do grupo de apoio, continua) ... Foram muito boas, me ajudaram muito, me deram vários conselhos, muito apoio, já que minha mãe não poderia tá vindo direto, mas elas me deram muito apoio, também!" (Maria)

Por vezes, as diferenças individuais e a convivência prolongada em certos momentos dificultou os relacionamentos, levando a conflitos no ambiente do alojamento. Nilce, vivendo uma união consensual turbulenta e estando o companheiro na ocasião desempregado, teve dificuldade de se relacionar com outras mães, encontrando na filha internada que lutava pela vida o principal motivo para superação dos problemas.

"Tem hora que a gente bate uma com a outra, mais eu relevo. Eu relevo, eu saio, eu venho aqui (UIN). \{ \} Quando eu vejo minha filha .. eu supero isso, tudinho, é minha força. Quando eu estou deprimida, venho, olho pra ela, converso com ela, e saio. Já me sinto um pouco mais aliviada." (Nilce)

Os resultados apontaram que ser mãe acompanhante do RNPT/BPN caracterizou-se como uma experiência difícil e dolorosa, decorrente da separação do convívio familiar cotidiano, do confinamento no espaço hospitalar e alguns conflitos gerados nas inter-relações. Apesar de tudo, a priori- dade para as mães do estudo era estar com o filho, não admitindo a possibilidade de sair de alta hospitalar, deixando o filho hospitalizado. Durante todo o processo de permanência da mãe e da internação do recém-nascido na unidade neonatal, o apoio formal fornecido pelos profissionais envolvidos e o informal recebido dos familiares e companheiras mostrou-se fundamental num aprendizado compartilhado.

\section{Discussão}

Nessa trajetória, foi percebido que a condição de ser mãe acompanhante do RNPT/BPN se desdobra num curtíssimo espaço de tempo, em múltiplos significados frente às circunstâncias diferenciadas atribuídas pelas mães no cotidiano vivido.

Compreende-se que nem a mãe, nem a família do prematuro são preparadas para viverem mudanças tão súbitas ao adentrarem no hospital, pois inicialmente sonham com o nascimento de um filho normalmente esperado, saudável e com traços físicos familiares. Os sentimentos evocados neste estudo foram coerentes e coincidentes com alguns estudos da literatura que se aproximaram de uma visão holística no cuidado à família, descrevendo as mudanças geradas na dinâmica familiar com a separação, durante o processo de hospitalização. Porém, percebe-se que em circunstâncias especiais os sentimentos e problemas se intensificam.

O impacto da experiência entre mães acompanhantes no contexto de uma unidade de internação pediátrica mostrou uma reviravolta na vida familiar, obrigando a mãe a modificar seus hábitos e sua relação com os familiares, em função do curso de sua vida mudar, tendo que se afastar das atividades do dia-a-dia, da família, dos amigos, da casa, do trabalho, quando o filho precisou ser internado em um hospital. 18

Porém, o que se acrescenta com relação à problemática vivida pela mãe acompanhante no contexto estudado, refere-se ao fato de essa mulher sofrer uma separação radical do meio social em que vivia, posterior à sua condição inicial de estar grávida e esperando um filho que imagina sadio e normal. Todavia, o parto se dá de forma prematura, tendo ela que permanecer no hospital, sem que receba um suporte formal adequado, como está estabelecido pelas diretrizes da política nacional de humanização da assistência hospitalar do Ministério da Saúde, 19 sendo as ações pontuais.

Nessa perspectiva, o processo de humanização é a filosofia ideal quando incorporada ao cuidado centrado na família, tendência da enfermagem 
pediátrica. 20,21 Porém, os métodos para sua implementação ainda não se acham bem estabelecidos na prática para quem trabalha com famílias em situações de crise em diferentes realidades. 22

É possivel que a ansiedade decorrente do afastamento materno do lar, viesse a ser minimizada com a flexibilização do horário, permitindo o retorno da mãe durante a noite para o domicílio, no caso daquelas residentes na região metropolitana do Recife. Como entre as mães de baixa renda a ida diária ao hospital significa gasto com transporte, essa dificuldade poderia ser diminuida com o fornecimento de recursos para o transporte, alimentação e orientações, havendo a necessidade de um trabalho articulado com a rede básica de saúde e outros setores sociais. 23

No presente estudo, a carência familiar parecia acentuar-se entre as mães acompanhantes procedentes das localidades mais distantes, por ser o hospital referência no estado para o atendimento à gravidez de risco. Essas mães recebiam visitas familiares esporadicamente, dificultadas na maioria das vezes por problemas de deslocamento e gastos com passagens, já que a maior parte da clientela era de baixo poder aquisitivo e as viagens comprometiam o orçamento familiar. A questão da hospitalização do filho revelou-se como um problema agravante para essas mães acompanhantes.

$\mathrm{O}$ fato reflete o que se discute com relação às falhas na organização da assistência perinatal, concentrando-se nos grandes centros os serviços de referência à gestação de risco, deixando as localidades mais distantes desprovidas de hospitais equipados para esse tipo de atendimento. Sendo assim, o encaminhamento dessas mães é quase inevitável e, muitas vezes, a internação de uma gestante de risco pode ocorrer antes do parto, na tentativa de evitar que ocorra prematuramente.

Evidencia-se, no contexto estudado, que o apoio recebido da família foi um suporte social imprescindível, sendo o primeiro a ser utilizado pelas mães acompanhantes, pois sentimentos de afeto e de estima estavam presentes nesse tipo de suporte, indicativo da superação dos problemas, trazendo alívio para o sofrimento vivido. Contudo, ressalta-se que a força que a mãe recebe pode vir também dos profissionais interessados em lhe fornecer algum suporte, para que ela vivencie o seu papel de acompanhante, possibilitando o enfrentamento da situação. 24 Entretanto, muitas vezes a pressão institucional ou as normas subjetivas podem exercer mais influência sobre as intenções do profissional do que as suas atitudes pessoais. 25,26

No contexto estudado, os profissionais raramente discutem ou possibilitam às mães acompanhantes poderem ir em casa, visitar seus familiares. Quando isso ocorre, é devido a tentativas insistentes de algumas mães que se mostram mais inquietas diante da situação e reivindicam constantemente essa necessidade. É certo que uma parcela significativa procede de lugares distantes e afastados do hospital. Porém, acredita-se ser viável tal afastamento para aquelas que o desejarem, sendo estimuladas a concretizarem suas necessidades antes do início da sucção ao seio materno, cujo processo em relação ao prematuro é mais demorado pela imaturidade e dificuldade de coordenar os reflexos de sucção, respiração e deglutição. Trata-se aqui de defender uma estratégia de ação que contribua para humanização e integralidade da assistência à tríade mãe/filho/ família, por esse processo de permanência prolongada da mãe acompanhante sempre se mostrar dolorido, sofrido e desgastante, até a concretização da alta do RNPT/BPN.

A percepção materna do alojamento como uma prisão ocorreu devido ao isolamento, um dos determinantes causadores do sofrimento, como apontado nas falas. Porém, mesmo diante de tal entendimento, elas não admitiam a possibilidade de alta sem o filho, fenômeno explicado pela visão do senso de dever moral da mãe para com o filho. 27

Quando se permite concretamente às mães acompanhantes assumirem algumas responsabilidades para com o filho, tais como, cuidados com a higiene, a troca de fraldas, a alimentação por copinho, ou seringa, supervisionados por um profissional da enfermagem, desmistifica-se entre elas a percepção de estarem prisioneiras no contexto da instituição, descartando a ociosidade e dando lugar ao sentimento de estarem sendo úteis ao participarem dos cuidados prestados ao filho. Mas, para que isso ocorra, a equipe da unidade neonatal deve incorporar a sua prática e a sua filosofia de trabalho assistir integralmente o cuidado à tríade mãe/filho/família.

Outro aspecto importante a ser discutido deve-se aos efeitos positivos gerados quando se institui um grupo de apoio às mães e família. Gradativamente, o estudo mostrou que o alojamento materno passou a ser visto como um espaço de novas amizades, aconselhamentos com troca de experiência, minimizando desse modo os efeitos indesejáveis da hospitalização. ${ }^{11}$

Existem, portanto, situações no ambiente hospitalar que sinalizam para outras demandas do ser humano fragilizado e que fogem ao seu controle. E os profissionais envolvidos com o cuidar, não podem perder de vista a compreensão dessas necessidades, dando oportunidade de sistematizar o cuidado numa 
perspectiva integral, humanizada e com qualidade, de modo que, na prática clínica, estratégias inovadoras possam e devam ser desenvolvidas pelos profissionais de saúde.

\section{Considerações finais}

Sob a ótica da abordagem qualitativa, compreendese a essência do sofrimento humano que envolve a problemática da prematuridade e do BPN, no período que vai do nascimento à hospitalização. Esse novo olhar permite questionar, na esfera hospitalar, o enfoque do cuidado centrado apenas na criança, desconsiderando as repercussões do nascimento e da hospitalização dessas crianças na estrutura e dinâmica familiar.

Traçando um caminho pouco percorrido na prática profissional das unidades neonatais no país, no que se refere à assistência à tríade mãe/recémnascido/família, evidenciou-se a necessidade de elucidar o significado de ser mãe acompanhante no contexto estudado, no qual se inseriu a escuta como terapia, para atender às demandas dessa mãe acompanhante, bem como dos familiares, dentro das suas possibilidades de participação junto a um grupo de apoio multidisciplinar. Não é um trabalho fácil, pois lidar com emoções requer ações rápidas e eficazes. Daí, a necessidade de ser desenvolvido por uma gama de profissionais, entre enfermeiras, psicólogas,

\section{Referências}

1. FIOCRUZ (Fundação Oswaldo Cruz). Assistência perinatal e neonatologia no Brasil. Rio de Janeiro: Programa Radis; 1999.

2. UNICEF (Fundo das Nações Unidas para Infância). Mortalidade neonatal em cinco maternidades da cidade do Recife, 1994. Brasília (DF); 1996.

3. Lima ALR, Taddei JAAC. Tendência secular do peso ao nascer na Maternidade de São Paulo. Rev Paul Pediatr 1998; 16: 127-36.

4. Araújo BF, Bozzetti MC. Mortalidade neonatal precoce no município de Caxias do Sul: um estudo de coorte. J Pediatr [Rio J] 2000; 76: 200-6.

5. Scochi CGS. A humanização da assistência hospitalar ao bebê prematuro: bases teóricas para o cuidado de enfermagem [tese livre docência]. Ribeirão Preto: Escola de Enfermagem de Ribeirão Preto da Universidade de São Paulo; 2000.

6. Bradt JO. Tornando-se pais: famílias com filhos pequenos. In: McGoldrick M, Carter B. As mudanças no ciclo de vida familiar: uma estrutura para terapia familiar. Porto Alegre: Artes Médicas; 2001. p. 206-21 assistentes sociais, neonatologistas, terapeutas ocupacionais, nutricionistas, e outros.

Desse modo, o estudo aponta para uma ação humana de cuidar, cujo aprendizado coletivo se dá de forma concreta e positiva num contexto formal e cuja experiência não termina aqui, podendo servir como subsídio para outras realidades. Salienta-se que esses achados foram apresentados durante uma reunião clínica realizada para os profissionais de saúde que atuam na unidade neonatal e na maternidade do hospital onde se deu o estudo, com o intuito de envolver e ampliar a participação coletiva.

Enfim, os depoimentos transcritos não são de situações humanas imprevistas e individuais, mas representam os depoimentos de mães que junto aos seus familiares vivenciaram, vivenciam e vivenciarão a experiência marcante do nascimento de um recém-nascido com risco biopsicosocial.

\section{Agradecimentos}

Às mães acompanhantes e à Coordenação de Aperfeiçoamento de Pessoal de Nível Superior (CAPES) pelo apoio técnico e financeiro como bolsista do Programa Institucional de Capacitação Docente e Técnica (PICDT) da Universidade Federal de Pernambuco.

7. Baldini SM, Krebs VLJ. Reações psicológicas nos pais de recém-nascidos internados em unidade de terapia intensiva. Pediatr Mod 2000; 36: 242-6.

8. Lamy ZC, Gomes R, Carvalho M. A percepção de pais sobre a internação de seus filhos em unidade de terapia intensiva neonatal. J Pediatr [Rio J] 1997; 73: 293-8.

9. Javorski M. Os significados do aleitamento materno para as mães de prematuros em cuidado Canguru [dissertação mestrado]. Ribeirão Preto: Escola de Enfermagem de Ribeirão Preto da Universidade de São Paulo; 1997.

10. Júnior AB, Matheus MCC. Comunicação. In: Cianciarullo TI. Instrumentos básicos para o cuidar: um desafio para a qualidade de assistência. São Paulo: Atheneu; 2000. p. 6173.

11. Vasconcelos MGL. Implantação de um grupo de apoio à mãe acompanhante de recém-nascido pré-termo e de baixo peso em um hospital amigo da criança na cidade de Recife, PE [tese doutorado]. Ribeirão Preto: Escola de Enfermagem de Ribeirão Preto da Universidade de São Paulo; 2004.

12. Minayo MCS. O desafio do conhecimento: pesquisa qualitativa em saúde. São Paulo: Hucitec; 1994. 
13. Chizzotti A. Pesquisa em ciências humanas e sociais. São Paulo: Cortez; 2000.

14. Lobiondo-Wood G, Haber J. Pesquisa em enfermagem: métodos, avaliação crítica e utilização. Rio de Janeiro: Guanabara Koogan; 2001.

15. Ministério da Saúde. Estatuto da criança e do adolescente. Brasília (DF); 1990.

16. Polit DF, Beck CT, Hungler BP. Fundamentos de pesquisa em enfermagem: métodos, avaliação e utilização. Porto Alegre: Artmed; 2004.

17. Bardin L. Análise de conteúdo. Lisboa: Edições 70; 1977.

18. Oliveira I, Angelo M. Vivenciando com o filho uma passagem difícil e reveladora - a experiência da mãe acompanhante. Rev Esc Enferm USP 2000; 34: 202-8.

19. Ministério da Saúde. Secretaria de Assistência à Saúde. Programa Nacional de Humanização da Assistência Hospitalar (PNHAH). Brasília (DF); 2001.

20. Newton MS. Family-centered care: current realities in parent participation. Pediatr Nurs 2000; 26: 164-8.

21. Marino BL, Marino EK. Parent's report of children's hospital care: what it means for your practice. Pediatr Nurs 2000; 26: 195-8.
22. Pauli MC, Bousso RS. Crenças que permeiam a humanização da assistência em unidade de terapia intensiva pediátrica. Rev Latinoam Enferm 2003; 11: 280-6.

23. Furlan CEFB, Scochi CGS, Furtado MCC. A percepção dos pais sobre a vivência no método Mãe-Canguru. Rev Latinoam Enferm 2003; 11: 444-52.

24. Scochi CGS, Kokuday MLP, Riul MJS, Rossanez LSS, Fonseca LMM, Leite AM. Incentivando o vínculo mãefilho em situação de prematuridade: as intervenções de enfermagem no hospital das clínicas de Ribeirão Preto. Rev Latinoam Enferm 2003; 11: 539-43.

25. Rossato-Abéde LM, Angelo M. Crenças determinantes da intenção da enfermeira acerca da presença dos pais em unidades neonatais de alto-risco. Rev Latinoam Enferm 2002; 10: 48-54.

26. Gaíva MAM, Scochi CGS. Processo de trabalho em saúde e enfermagem em UTI neonatal. Rev Latinoam Enferm 2004; 12: 469-76.

27. Coyne IT. Partnership in care: parents views of participation in their hospitalized child's care. J Clin Nurs 1995; 4: 71-9.

Recebido em 9 de dezembro de 2004

Versão final apresentada em 4 de janeiro de 2006

Aprovado em 2 de fevereiro de 2006 